\title{
Anthropometric and Health-Related Behavioral Factors in the Explanation of Social Inequalities in Low Birth Weight in Children with Prenatal Alcohol Exposure
}

\author{
Manuela Pfinder ${ }^{1,2}$
}

1 Bielefeld Graduate School in History and Sociology, Faculty of Sociology, University of Bielefeld, P.O. Box 10-01-31, Bielefeld 33501, Germany; E-Mail: manuela.pfinder@uni-bielefeld.de; Tel.: +49-176-6155-1512

2 Department of Pediatrics, University Hospital Munster, Albert-Schweitzer-Campus 1, Munster 48129, Germany

Received: 12 November 2013; in revised form: 18 December 2013 / Accepted: 25 December 2013 / Published: 8 January 2014

\begin{abstract}
There is evidence for social inequalities in the health status of children with prenatal alcohol exposure (PAE). This study aimed to describe social inequalities in low birth weight (LBW) in children/adolescents with PAE and to examine the contribution of anthropometric and health-related behavioral factors to the explanation of social inequalities. A total of 2,159 participants with parental self-reported moderate to regular PAE (enrolled in the cross-sectional German Health Interview and Examination Survey for Children and Adolescents) were examined. At similar levels of PAE, the risk of LBW was significantly increased in subjects with a low socioeconomic status (SES) (adjusted odds ratio (OR) 2.78, 95\% confidence interval (CI) 1.59, 4.86) and middle SES (adjusted OR 2.04, $95 \%$ CI 1.28, 3.24). Maternal height, maternal body mass index (BMI) and smoking during pregnancy mediated the association. The mediating effect of maternal height was $12.5 \%$ to $33.7 \%$. Maternal BMI explained $7.9 \%$ of the socioeconomic difference in LBW between the high and low SES groups in children with PAE. The mediating effect of smoking during pregnancy was $17.3 \%$ to $31.5 \%$. Maternal height, maternal BMI and smoking during pregnancy together explained $24.4 \%$ to $60.1 \%$ of the socioeconomic differences in LBW in children with PAE. A large proportion of the socioeconomic differences in LBW in children with PAE can be attributed to anthropometric and health-related behavioral factors.
\end{abstract}


Keywords: low birth weight; social inequalities; alcohol; pregnancy; smoking; maternal height

\section{Introduction}

It is known that maternal alcohol intake during pregnancy is associated with a broad range of irreversible disorders and serious impairments in the offspring since Lemoine et al. [1] reported on the adverse effects of prenatal alcohol exposure (PAE); these effects are covered by the umbrella term "fetal alcohol spectrum disorders" (FASD). Growth retardation and low birth weight (LBW) were among the first observed negative effects of PAE [1-10]. Although alcohol intake during pregnancy was reported to be most prevalent in women with a high socioeconomic status (SES) [11-17], the adverse effects of PAE appeared mostly in the offspring with a low socioeconomic background [18-25]. A study on the influence of socioeconomic factors on the effects of PAE showed that the risk of giving birth to a child with alcohol-related disorders, alcohol-related birth defects and fetal alcohol syndrome (FAS), at similar levels of maternal alcohol intake during pregnancy, is up to 15.8 times higher in women from the lower social class compared with women with a high SES [20]. For instance, mean birth weight was shown to be significantly decreased in alcohol exposed subjects from the lower social class compared with those from the upper social class [20]. In turn, LBW was found to be associated with a considerable number of diseases over the life course, as described by the theory on fetal origins of adult diseases (FOAD) [26-34]. In line with the FOAD theory, a study from Germany reported that the risk of alcohol-related disorders in children with similar levels of PAE is 2.4 times higher in those with LBW [34]. Thus, LBW may account for various adverse outcomes associated with FASD over the life course of individuals with PAE. This emphasizes the need to explore why individuals exposed to comparable levels of alcohol in utero show a higher risk of LBW when they have a lower socioeconomic background.

Although SES has no direct effect on LBW, a lower SES can be seen as a proxy for risk factors that cause LBW, such as adverse conditions and health-related behaviors. Reasons for the increased risk of LBW in offspring with PAE might be maternal health-related behavioral factors and parental anthropometrics. Both types of factors are hypothesized to contribute to the explanation of social inequalities in LBW in children with PAE. In addition, smoking during pregnancy is a known adverse health-related behavior. The association between the risk of LBW and maternal smoking during pregnancy is well established [35-41], suggesting an increased risk of LBW in the offspring of smokers. Smoking during pregnancy is also strongly associated with SES, indicating a higher prevalence of smokers during pregnancy in the lower social class [35,42]. Therefore, it is reasonable to hypothesize that tobacco smoke exposure during pregnancy mediates the socioeconomic differences in LBW. As smoking during pregnancy was found to exacerbate the effect of PAE on LBW [18,19,43-46], its contributory power to the socioeconomic differences in LBW might be stronger in subjects with PAE than in the more general population. Therefore, it is necessary to test this hypothesized mediation in a subsample of subjects with PAE. 
Besides maternal smoking during pregnancy, parental anthropometrics may also play a role in the association between SES and LBW. Parental anthropometrics [height, weight, body mass index (BMI), gestational gain in weight] are known to affect the offspring's birth weight $[39,41,47-53]$. The association between increasing gestational gain in weight and increasing birth weight is also well established $[41,43,45]$. Shorter women and underweight women are at higher risk of giving birth to a child with LBW compared with their "average" counterparts [39,50,54]. Paternal height and weight are also relevant predictors of birth weight, suggesting that offspring's birth weight increases with increasing height and weight of the father [50,52]. Unfavorable anthropometric conditions, such as insufficient gestational gain in weight, short stature and very low weight (a BMI below the recommended levels), are more prevalent in the lower social class [55-57]. The SES of an individual is highly correlated over the life course and predicts anthropometric conditions which remain fixed (to some extent) at a certain point in life (e.g., height) and these factors may, in turn, account for the risk of LBW. Therefore, it is reasonable to hypothesize that parental anthropometric factors mediate the socioeconomic differences in LBW. As maternal height and weight/BMI have an impact on the levels of blood alcohol concentration (BAC) and these factors alter the levels of BAC in the fetus [24], the contributory power to the socioeconomic differences in LBW might be stronger in individuals with PAE than in the more general population; therefore, it is necessary to test the hypothesized mediation in a subsample of subjects with PAE.

All anthropometric and health-related behavioral factors may account for social inequalities in the health of children with PAE, if they are related to LBW and socioeconomic conditions.

To examine the question as to why the risk of LBW is greater in offspring with a lower SES at similar levels of PAE, it is necessary to focus on subjects with PAE only, as a multiplicity of risk factors associated with a low SES increase a person's vulnerability to the adverse effects of PAE by creating a biological milieu within which alcohol develops its major effects [18,19,22-25].

An explanation of the socioeconomic variations in LBW in children with PAE is essential to understand and make recommendations for public health actions to reduce social inequalities in LBW among children with PAE, and to avoid an increase of health inequalities over the life course. Although social inequalities in LBW among alcohol-exposed newborns have been reported, the present study is the first to investigate an explanation for the socioeconomic differences in LBW.

The aim of this study was to detect whether social differences exist in the distribution of LBW among children with PAE, and to explain social inequalities in LBW by identifying the contributions of health-related behavior and parental anthropometrics.

\section{Methods}

\subsection{KIGGS Study}

This study is based on data from the German Health Interview and Examination Survey for Children and Adolescents (KiGGS); this is a nationally representative cross-sectional study including 17,641 children/adolescents (aged 0-17 years) and their parents. The KiGGS study was commissioned by the German Federal Ministry of Health and was designed and conducted by the Robert Koch-Institute. The design of the survey, the process of recruitment and the fieldwork are described in 
detail elsewhere [56]. Briefly, four study teams followed a random route plan of 167 primary sample points in the years 2003-2006. The study consists of the KiGGS core survey and five additional in-depth modules with subsamples of the main study. Age-appropriate questionnaires were designed to be filled in by the parents, or by the children/adolescents when aged $\geq 11$ years. Additional information on the health status of the children and adolescents was gained from medical examinations, anthropometric measurements and laboratory tests. Of the total sample of 28,299 participants, 17,641 children/adolescents and their parents were surveyed (response rate 66.6\%).

Written informed consent according to the Helsinki Declaration was obtained from the participants and their parents or guardians before the individuals entered the study. Approval for the KiGGS study was obtained from the Ethics Committee of the Charité/Universitätsmedizin Berlin (Germany) and the Federal Office for the Protection of Data (20 February 2003).

\subsection{Sample}

Of the 17,641 participants, 2,331 individuals were exposed to alcohol before birth. PAE was measured through retrospective parental self-reports, questioning whether the mother drank alcohol during pregnancy. Possible answer categories were: "regular", "moderate" or "no alcohol" intake during pregnancy. The terms "moderate" and "regular" are derived from self-report and may, therefore, be affected by the respondent's subjective evaluation of such quantities. Participants without information on SES or birth weight, or information provided by non-biological parents and twin and multiple births were excluded from the analysis. This left a study population of 2,159 subjects with PAE for the analysis.

\subsection{Variable Measurements}

\subsubsection{Low Birth Weight (LBW)}

Parents were asked to give information on the birth weight of their child. LBW was set to $\leq 2,700 \mathrm{~g}$ after calculating the 10th percentile based on information from 16,877 questionnaire responders in the overall cohort study on birth weight [34]. Similar to other studies, LBW was defined by the 10th percentile of birth weight in the entire study population $[35,36]$; the result was comparable to the 10 th percentiles of birth weight in a study from Denmark ( $\leq 2,700 \mathrm{~g}$ and $\leq 2,910 \mathrm{~g}$, respectively) [35] and from Italy $(<2,600 \mathrm{~g})$ [57].

\subsubsection{Socioeconomic Status (SES)}

The SES was measured with Winkler's index [58,59] which was readjusted for the KiGGS study [60]. Winkler's index is a widely used social class index based on the validated Scheuch index [61]. Winkler's index is defined and measured by the net income, the basic and vocational education, and by the profession. Each of the three dimensions scores 1-7 points. The index ranges from 3-21 points: 3-8 points indicate the low SES group, 9-14 points indicate the middle SES group, and 15-21 points indicate the high SES group [61,62]. The variable is derived from the main wage earner in the household and is categorized into high, middle and low. Further details on the measurement and classification can be found in [62]. 


\subsubsection{Anthropometrics}

Parental anthropometrics might be associated with the birth weight of the child and the SES. Gestational gain in weight (categorical variable: low (<10 kg), medium $(10-15.9 \mathrm{~kg})$, high $(>16 \mathrm{~kg})$ ) [54], maternal height (continuous variable), paternal height (continuous variable), maternal BMI (categorical variable: underweight (BMI < 18.5), not underweight (BMI $\geq 18.5)$ ) [63] and paternal BMI (categorical variable: underweight (BMI < 18.5), not underweight (BMI $\geq 18.5)$ ) [63] were measured by parental self-report questionnaires.

\subsubsection{Maternal Health-Related Behaviors}

Information on maternal health-related behaviors during pregnancy was restricted to maternal smoking during pregnancy (categorical variable: no, moderately, regularly) and was measured by self-report questionnaires.

\subsubsection{Covariates}

The models were adjusted for maternal age at child's birth (continuous variable), gender of the child (categorical variable: male, female), ethnicity (categorical variable: German, Slavic, Turkish, Others) and parity (categorical variable: $0,>0$ ).

\subsection{Statistical Analyses}

Potential mediation was tested by the Baron and Kenny criteria [64]. Each of the anthropometric and health-related behavioral factors is accepted as a mediator: (1) if the variable is affected by the independent variable; (2) if the independent variable affects the dependent variable; (3) if the mediator affects the dependent variable; and (4) if the effect of the independent variable on the dependent variable is decreased after adjustment for the mediator.

In the first stage, according to Baron and Kenny [64], the frequency distribution by levels of SES (independent variable) of anthropometric and health-related behavioral factors (potential mediators) and confounders was established (first criterion). Also, the association between the SES and LBW (dependent variable) was tested (second criterion). The one-way-analysis of variance (ANOVA) was applied to test trends across levels of SES for continuous factors and the chi-squared test was used for categorical factors (Table 1). The univariate association between anthropometric and health-related behavioral factors and LBW was examined by applying the ANOVA for continuous factors and the chi-squared test for categorical factors (Table 2).

Multivariate logistic regressions were used to calculate the odds ratio (OR) and the $95 \%$ confidence interval (CI) of LBW for levels of SES (the highest SES was considered the reference) with adjustment for potential confounders (ethnicity, child's gender, parity, maternal age at birth of the child) as shown in model 1. Thereafter, model 1 was adjusted for possible explanatory variables separately, to examine the association with LBW (third criterion) and also to examine the contribution of each possible explanatory variable to the explanation of social inequalities in LBW (fourth criterion). All mediators were added to model 1 to identify the total contribution of the mediating variables to the explanation of social inequalities in LBW. The change (decrease or increase) in the OR for parental SES with the higher 
risk of LBW was calculated with the formula $100 \times\left(\left(\mathrm{OR}_{\text {(model1) }}-\mathrm{OR}_{\text {(adjusted model })}\right)\left(\mathrm{OR}_{(\text {model1) }}-1\right)\right)$ (Table 3) [65]. To examine the multivariate association between the mediators and LBW in children with PAE, logistic regression analysis was applied (Table 4). The Statistical Package of Social Sciences (SPSS) version 19.0 was used for all statistical analyses.

Table 1. Relation between independent and dependent variables, and potential mediators and confounders.

\begin{tabular}{|c|c|c|c|c|}
\hline Total $N=2,159$ & $\begin{array}{c}\text { High SES } \\
\mathbf{N}=\mathbf{8 2 9} \\
(\mathbf{3 8 . 4 \% )} \\
\end{array}$ & $\begin{array}{c}\text { Middle SES } \\
\qquad \begin{array}{c}\text { N }=960 \\
(44.5 \%)\end{array} \\
\end{array}$ & $\begin{array}{c}\text { Low SES } \\
\mathbf{N}=\mathbf{3 7 0} \\
(\mathbf{1 7 . 1 \% )} \\
\end{array}$ & $\begin{array}{l}p \text { for } \\
\text { Trend }\end{array}$ \\
\hline \multicolumn{5}{|l|}{ Pregnancy characteristics } \\
\hline Low birth weight $(\%)$ & 5.8 & 8.9 & 11.1 & 0.004 \\
\hline Maternal age at birth of the child (years) & $31.1(4.5)$ & $28.8(4.8)$ & $27.0(5.0)$ & $<0.001$ \\
\hline Parity $(\%>0)$ & 67.2 & 71.2 & 72.1 & 0.147 \\
\hline Gender (\% male) & 48.4 & 48.6 & 52.7 & 0.339 \\
\hline \multicolumn{5}{|l|}{ Ethnicity (\%) } \\
\hline German & 87.8 & 91.3 & 78.5 & \multirow{4}{*}{$<0.001$} \\
\hline Slavic & 2.2 & 3.6 & 7.1 & \\
\hline Turkish & 0.4 & 1.2 & 6.3 & \\
\hline Others & 9.6 & 4.0 & 8.2 & \\
\hline \multicolumn{5}{|l|}{ Anthropometrics } \\
\hline Maternal height $(\mathrm{cm})$ & $168.4(6.1)$ & $167.1(6.0)$ & $165.6(6.3)$ & $<0.001$ \\
\hline Paternal height $(\mathrm{cm})$ & $181.5(7.1)$ & $179.7(7.1)$ & $177.6(7.1)$ & $<0.001$ \\
\hline Maternal BMI (\% underweight) & 2.2 & 2.1 & 3.9 & 0.151 \\
\hline Paternal BMI (\% underweight) & 0.3 & 0.4 & 0.4 & 0.920 \\
\hline \multicolumn{5}{|l|}{ Gestational gain in weight (\%) } \\
\hline Low & 17.3 & 17.0 & 19.3 & \multirow{3}{*}{0.014} \\
\hline Medium & 59.0 & 52.5 & 50.9 & \\
\hline High & 23.7 & 30.5 & 29.8 & \\
\hline \multicolumn{5}{|l|}{ Health-related behavior } \\
\hline \multicolumn{5}{|l|}{ Smoking during pregnancy (\%) } \\
\hline No & 90.8 & 79.7 & 62.4 & \multirow{3}{*}{$<0.001$} \\
\hline Moderately & 7.2 & 14.6 & 20.7 & \\
\hline Regularly & 2.1 & 5.7 & 16.9 & \\
\hline
\end{tabular}

Notes: $\mathrm{BMI}=$ body mass index. Data were missing for maternal age at birth of the child $(\mathrm{N}=25)$, parity $(\mathrm{N}=376)$, ethnicity $(\mathrm{N}=12)$, maternal height $(\mathrm{N}=25)$, paternal height $(\mathrm{N}=239)$, gestational gain in weight $(\mathrm{N}=149)$, maternal BMI $(\mathrm{N}=37)$, paternal BMI $(\mathrm{N}=271)$, and smoking during pregnancy $(\mathrm{N}=9)$. Values are percentages for categorical factors, or means (with standard deviations) for continuous factors. $p$-values for trend are derived from chi-squared tests for trend (categorical factors) or from the linear trend test of the one-way analysis of variance.

\section{Results}

Table 1 shows the relation between the independent and dependent variables, and potential mediators and confounders. Of the 2,159 participants whose mothers consumed alcohol during pregnancy, $17.1 \%$ are from the low social class, $44.5 \%$ have a social middle-class background, 
and $38.4 \%$ are from the highest social class. The total prevalence of LBW was $8.1 \%$ and followed a social gradient, with the highest prevalence in the lowest SES group: prevalence rates of LBW are $5.8 \%$ in the high SES group, $8.9 \%$ in the middle SES group, and $11.1 \%$ in the low SES group ( $p$ for trend 0.004). Women with a higher SES were older when they gave birth to their child. Of the offspring with a high SES, $87.8 \%$ are German compared to $91.3 \%$ of the middle SES offspring and $78.5 \%$ of the low SES offspring. Parents from the highest social class are taller than parents from the middle and low social class $(p<0.001)$. The prevalence of low gestational weight gain was highest $(19.3 \%)$ in the low social class with $(p=0.014)$. Concerning maternal health-related behavior during pregnancy, mothers from the low social class have the highest moderate and regular smoking rate during pregnancy ( $p$ for trend all $\leq 0.001$ ).

Table 2 presents the univariate associations between LBW and potential mediators. Women who gave birth to a child with LBW were shorter and had a higher prevalence of underweight $(p<0.001)$. The fathers of children with LBW were shorter than the fathers of children with a higher birth weight $(p<0.016)$. The prevalence of low gestational weight gain was $40.3 \%$ in women who gave birth to a child with LBW compared with a prevalence of $15.6 \%$ of low gestational weight gain in women who did not deliver a child with LBW $(p<0.001)$.

Table 2. Relation between low birth weight and potential mediators.

\begin{tabular}{cccc}
\hline Total N= 2,159 & $\begin{array}{c}\text { Low Birth Weight } \\
\text { N= 174 (8.1\%) }\end{array}$ & $\begin{array}{c}\text { No Low Birth Weight } \\
\mathbf{N = 1 , 9 8 5}(\mathbf{9 1 . 9 \% )}\end{array}$ & $\begin{array}{c}\boldsymbol{p} \text { for } \\
\text { Trend }\end{array}$ \\
\hline Anthropometrics & & & \\
Maternal height (cm) & $164.3(5.9)$ & $167.6(6.1)$ & $<0.001$ \\
Paternal height (cm) & $178.8(6.9)$ & $180.3(7.2)$ & 0.016 \\
Maternal BMI (\% underweight) & 6.6 & 2.1 & $<0.001$ \\
Paternal BMI (\% underweight) & 0.3 & 0.0 & 0.481 \\
Gestational gain in weight (\%) & & & \\
Low & 40.3 & 15.6 & \\
Medium & 42.3 & 55.8 & \\
High & 17.4 & 28.6 & \\
Health-related behavior & & & $<0.001$ \\
Smoking during pregnancy (\%) & & & \\
No & 65.5 & 12.2 & \\
Moderately & 19.5 & 5.5 & \\
Regularly & 14.9 & & \\
\hline
\end{tabular}

Notes: $\mathrm{BMI}=$ body mass index. Data were missing for maternal height $(\mathrm{N}=25)$, paternal height $(\mathrm{N}=239)$, maternal BMI $(\mathrm{N}=37)$, paternal BMI $(\mathrm{N}=271)$, gestational gain in weight $(\mathrm{N}=149)$, and smoking during pregnancy $(\mathrm{N}=9)$. Values are percentages for categorical factors, or means (with standard deviations) for continuous factors. P-values for trend are derived from chi-squared tests for trend (categorical factors) or from the linear trend test of the one-way analysis of variance. 
Table 3. Change in the odds ratio (OR) related to levels of socioeconomic status (SES) with low birth weight after separate adjustment for potential mediators.

\begin{tabular}{|c|c|c|c|c|c|}
\hline & \multicolumn{5}{|c|}{ SES } \\
\hline & High & Middle & $\begin{array}{l}\text { Percentage } \\
\text { Change }^{c}\end{array}$ & Low & $\begin{array}{c}\text { Percentage } \\
\text { Change }^{\mathrm{b}}\end{array}$ \\
\hline Model 1: maternal age at child's birth, ethnicity, parity, child's gender & 1.00 & $2.04(1.28,3.24)$ & & $2.78(1.59,4.86)$ & \\
\hline Model $1+$ maternal height ${ }^{\text {a }}$ & 1.00 & $1.91(1.19,3.06)$ & -12.5 & $2.18(1.22,3.90)$ & -33.7 \\
\hline Model $1+$ paternal height & 1.00 & $1.90(1.16,3.08)$ & -13.5 & $2.38(1.28,4.45)$ & -22.5 \\
\hline Model $1+$ maternal BMI ${ }^{\text {a }}$ & 1.00 & $2.14(1.33,3.42)$ & +9.6 & $2.64(1.49,4.68)$ & -7.9 \\
\hline Model $1+$ paternal BMI & 1.00 & $1.90(1.17,3.08)$ & -13.5 & $2.62(1.41,4.87)$ & -9.0 \\
\hline Model $1+$ gestational gain in weight $^{\text {a }}$ & 1.00 & $2.28(1.37,3.78)$ & +23.1 & $2.86(1.54,5.29)$ & +4.5 \\
\hline Model $1+$ smoking during pregnancy $^{a}$ & 1.00 & $1.86(1.17,2.98)$ & -17.3 & $2.22(1.25,3.96)$ & -31.5 \\
\hline Model $1+$ maternal height, maternal BMI, smoking during pregnancy & 1.00 & $1.79(1.11,2.89)$ & -24.4 & $1.71(0.94,3.13)$ & -60.1 \\
\hline
\end{tabular}

Notes: BMI = body mass index. Values are ORs with $95 \%$ confidence intervals. ${ }^{a}$ Significant relation to low birth weight $(p<0.05) .{ }^{b}$ Change in OR relates to the change of the OR relative to model 1 for middle and low SES after separate adjustment for potential mediators $100 \times\left(\left(\mathrm{OR}_{(\text {model 1) }}-\mathrm{OR}_{(\text {adjusted model })}\right) /\left(1-\mathrm{OR}_{(\text {model } 1)}\right)\right)$. 
Table 4. Logistic regression model fitted on low birth weight.

\begin{tabular}{|c|c|}
\hline & OR $(95 \%$ CI $)$ \\
\hline \multicolumn{2}{|l|}{ SES } \\
\hline High (reference) & 1.00 \\
\hline Middle & $1.79(1.11,2.89)$ \\
\hline Low & $1.71(0.94,3.13)$ \\
\hline Maternal age at birth of the child (years) & $1.01(0.97,1.06)$ \\
\hline \multicolumn{2}{|l|}{ Parity } \\
\hline 0 (reference) & 1.00 \\
\hline$>0$ & $0.49(0.32,0.75)$ \\
\hline \multicolumn{2}{|l|}{ Gender } \\
\hline Male (reference) & 1.00 \\
\hline Female & $1.60(1.08,2.35)$ \\
\hline \multicolumn{2}{|l|}{ Ethnicity } \\
\hline German (reference) & 1.00 \\
\hline Slavic & $1.24(0.55,2.80)$ \\
\hline Turkish & $1.40(0.46,4.30)$ \\
\hline Others & $1.43(0.72,2.84)$ \\
\hline Maternal height $(\mathrm{cm})$ & $0.91(0.88,0.95)$ \\
\hline \multicolumn{2}{|l|}{ Maternal BMI } \\
\hline Not underweight (reference) & 1.00 \\
\hline Underweight & $2.53(1.04,6.13)$ \\
\hline \multicolumn{2}{|l|}{ Smoking during pregnancy } \\
\hline No smoking (reference) & 1.00 \\
\hline Moderate smoking & $1.55(0.92,2.63)$ \\
\hline Regular smoking & $2.52(1.33,4.75)$ \\
\hline Constant B (SE) & $11.582(2.915)$ \\
\hline $\mathrm{N}$ & 1727 \\
\hline Nagelkerke's $\mathrm{R}^{2}$ & 0.106 \\
\hline
\end{tabular}

Note: $\mathrm{BMI}=$ body mass index. Values are odds ratios (ORs) with $95 \%$ confidence intervals.

Table 3 shows socioeconomic differences in LBW and the contribution of each potential explanatory factor to the explanation of social inequalities in LBW in children with PAE. The decrease in the ORs for SES indicates the explanatory power of the variables to the socioeconomic differences in LBW. When comparing LBW in the middle and low SES group with the high SES group, the adjusted OR for the low SES group was $2.78(95 \%$ CI 1.59, 4.86) and the adjusted OR for the middle SES group was $2.04(1.28,3.24)$. The separate adjustment for anthropometric and health-related factors shows that maternal height, maternal BMI and smoking during pregnancy, mediated the relationship between SES and LBW. After adjustment for confounders, paternal height and paternal BMI did not remain significantly related to LBW. Gestational gain in weight remained significantly related to LBW after adjustment for confounders, but did not result in a decrease of the ORs. Therefore, this variable could not be accepted as a mediator in the socioeconomic differences of LBW. The mediating effect of maternal height was $12.5 \%$ in the middle SES group and $33.7 \%$ in the low SES group. Maternal BMI caused a $7.9 \%$ decrease in the ORs in the low SES group. The mediating effect of smoking during pregnancy was $27.9 \%$ in the middle SES group and $31.5 \%$ in the low SES group. When all mediating 
variables, maternal height, maternal BMI and smoking during pregnancy, were included in the model, the OR decreased to $1.79(95 \%$ CI $1.11,2.89)$ in the middle SES group and to $1.71(0.94,3.13)$ in the low SES group, implying a decrease of $24.4 \%$ and $60.1 \%$, respectively.

Table 4 presents the model including all mediating variables from Table 3 (model $1+$ maternal height, maternal BMI, smoking during pregnancy) to demonstrate the associations between LBW in children with PAE and the mediating variables. The risk of LBW decreased with increasing maternal height (OR 0.91, 95\% CI 0.88, 0.95). The risk of LBW was greater in women with underweight (OR 2.53, 95\% CI 1.04, 6.13). Also, the risk of LBW increased in offspring exposed to alcohol whose mother also smoked regularly (OR 2.52, 95\% CI 1.33, 4.75).

\section{Discussion}

\subsection{Main Findings}

In this study, the risk of LBW was increased in the offspring with PAE from the low and middle social class compared with those from the high social class. Maternal height and smoking during pregnancy mediated the relationship between the SES and LBW in children with PAE. Maternal height explained $12.5 \%$ to $33.7 \%$ of the socioeconomic differences in LBW in children with PAE. Maternal BMI explained $7.9 \%$ of the socioeconomic differences in LBW between the low and high SES group in children with PAE. Smoking during pregnancy explained $17.3 \%$ to $31.5 \%$ of the socioeconomic differences in LBW in children with PAE. Both factors together contributed $24.4 \%$ to $60.1 \%$ to the explanation of socioeconomic differences in LBW in children with PAE.

\subsection{Strengths and Limitations}

The study is based on data from a very large and representative national sample. Studies on the reliability of alcohol measurements have demonstrated that drinking during pregnancy is often underreported [66-69]. However, the present study included only subjects with moderate to regular PAE and included a relatively large sample of 2,159 individuals.

The sample in this study could be confounded by various factors. For example, if reports on alcohol intake during pregnancy are related to levels of SES, the social distribution of alcohol-exposed individuals could be biased in unknown ways. Also, if reports on alcohol intake during pregnancy are related to the health status of the child, or to the health status and/or to the health behavior of the mother, or to all of these aspects, the estimates could be biased in unknown ways.

In the present study, maternal health-related behavior during pregnancy was restricted to smoking during pregnancy. Additional health-related behaviors (such as caffeine intake during pregnancy and dietary factors) might be relevant in the explanation of why children exposed to similar levels of alcohol before birth from the lower social class are at higher risk for LBW compared with offspring from the upper class. Therefore, additional studies are needed to investigate the role of a wider range of health-related behaviors during pregnancy in the explanation of social inequalities in LBW in children with PAE.

Because smoking during pregnancy was self-reported, underreporting might have occurred [70-73]. Therefore, the association between smoking during pregnancy and LBW might be underestimated and 
the "real" effect of smoking during pregnancy on LBW might be even stronger. If reports on smoking during pregnancy are associated with levels of SES, the results could be biased in unknown ways.

The multiple regression model only explained $10.6 \%$ of the variance in LBW, even though it was controlled for a large number of confounders.

\subsection{Discussion of the Main Findings}

The risk of LBW in the offspring of self-reported moderate to regular drinkers during pregnancy was greater in those with a low and middle SES. This result is in line with others who reported social inequalities in the effects of maternal alcohol intake during pregnancy [18-25]. This finding is also in agreement with another study showing decreased birth weight in alcohol-exposed subjects from the lower social class compared with the upper social class [20].

The present study has shown that the single effect of smoking during pregnancy explains a substantial amount $(17.3 \%$ to $31.5 \%)$ of the social gradient in LBW in children with PAE. The ingredients of tobacco smoke (e.g., carbon monoxide and nicotine) cause a decrease in birth weight as these factors are responsible for a reduction in blood flow/oxygen content, and nicotine exposure results in contraction of the placental vessels [74-77]. The considerable explanatory power ascribed to socioeconomic differences in LBW in children with PAE, that can be attributed to smoking during pregnancy, might be due to the greater toxic effects of smoking in subjects with PAE. Alcohol and tobacco smoke together are reported to have a greater toxic effect on birth weight, as the effect of alcohol is exacerbated by tobacco smoke [18,19,43-46]. Therefore, the role of smoking during pregnancy in the explanation of socioeconomic differences in LBW likely has considerable relevance and, thereby, contributes to our understanding of why children with PAE from the lower social class have a higher risk of LBW.

The present study shows that the single effect of maternal height explains a considerable amount $(12.5 \%$ to $33.7 \%)$ of the social gradient in LBW in children with PAE. In agreement with others $[37,38,78-81]$, the present study shows that taller women have a lower risk of giving birth to a child with LBW. The large explanatory power to socioeconomic differences in LBW in children with PAE that can be attributed to maternal height might be due to lower levels of BAC in taller women, resulting in lower levels of BAC in the fetus [23]. Thus, maternal height is likely to modify the effect of alcohol on the embryo/fetus; future research should investigate potential effect modifications of PAE by maternal height. The role of maternal height in the explanation of social inequalities in LBW appears to be relevant and helps elucidate why children with PAE from the lower social class are at higher risk of LBW.

Maternal BMI explains 7.9\% of the socioeconomic difference in LBW between the high and the low SES group in children with PAE; the finding of an increased risk of LBW in women with underweight concurs with other studies [37,82] and with a recent meta-analysis [83]. Underweight women might have a lack of growth-stimulating nutrients, which are responsible for the reduced birth weight of the embryo/fetus. Maternal BMI contributed to the explanation of socioeconomic differences in LBW in the low SES group only. Of the women in the present study, the prevalence of underweight was higher in the low social class than in the middle/high social class, but almost similar in the middle and high 
social class. Therefore, the explanation of the social gradient in LBW by maternal BMI is limited to the low SES group only.

Maternal anthropometrics, in terms of maternal height and BMI, as well as maternal health-related behavior, in terms of smoking during pregnancy, contributed to the explanation of social inequalities in LBW among children with PAE. A considerable amount $(24.4 \%$ to $60.1 \%)$ of the socioeconomic differences in LBW in children with PAE was explained by health-related behavioral and anthropometric factors together. Both factors seem to be of importance for the explanation of social inequalities in LBW in children with PAE.

\section{Conclusions}

This study has shown that LBW in children with PAE is subject to social inequalities. Maternal health-related behavior during pregnancy and maternal anthropometrics make a considerable contribution to our understanding of socioeconomic differences in LBW in children with moderate to regular PAE. LBW acts as a catalyst for diseases throughout the life course. The development of FASD in alcohol-exposed children is related to LBW and this study shows that smoking during pregnancy, lower maternal height, and being underweight trigger the risk of LBW. Both anthropometric and health-related behavioral factors might mediate the association between SES and alcohol-related disorders. To reduce social inequalities in the health of children with PAE at an early stage, it is important to inform women with a lower SES about the adverse effects of tobacco smoke and being underweight on the embryo/fetus. However, prevention campaigns related to the adverse effects of alcohol and tobacco smoke during pregnancy should be designed to reach all women from all social classes.

\section{Acknowledgments}

The author acknowledges support for the Article Processing Charge by the Deutsche Forschungsgemeinschaft and the Open Access Publication Funds of Bielefeld University Library. The author would like to thank Stefan Liebig and Reinhold Feldmann for supporting the idea of this study, and the reviewers for their careful review and helpful comments and suggestions to improve the manuscript.

\section{Conflicts of Interest}

The author declares no conflict of interest.

\section{References}

1. Lemoine, P.; Harousseau, H.; Borteyru, J.P.; Menuet, J.C. Les enfants de parents alcooliques: Anomalies observées à propos de 127 cas. Ouest. Med. 1968, 25,476-482.

2. Jacobson, J.L.; Jacobson, S.W. Effects of prenatal alcohol exposure on child development. Alcohol. Res. Health 2002, 26, 282-286.

3. Jones, K.L.; Smith, D.W. Recognition of the fetal alcohol syndrome in early infancy. Lancet 1973, 2, 999-1001. 
4. Larkby, C.; Day, N. The effects of prenatal alcohol exposure. Alcohol Health Res. World 1997, 21, 192-198.

5. Larroque, B.; Kaminski, M.; Lelong, N.; Subtil, D.; Dehaene, P. Effects on birth weight of alcohol and caffeine consumption during pregnancy. Amer. J. Epidemiol. 1993, 137, 941-950.

6. Löser, H. Alkohol und Schwangerschaft-Alkoholeffekte bei Embryonen, Kindern und Jugendlichen. In Alkohol und Alkoholfolgekrankheiten-Grundlagen-Diagnostik-Therapie; Singer, M.V., Teyssen, S., Eds.; Springer: Berlin/Heidelberg, Germany; New York, NY, USA, 1999; pp. 431-451.

7. Olegard, R.; Sabel, K.G.; Aronsson, M.; Sandin, B.; Johansson, P.R.; Carlsson, C.; Kyllerman, M.; Iversen, K.; Hrbek, A. Effect on the child of alcohol abuse during pregnancy: Retrospective and prospective studies. Acta Paediat. 1979, 68, 112-121.

8. Passaro, K.T.; Little, R.E.; Savitz, D.A.; Noss, J. The effect of maternal drinking before conception and in early pregnancy on infant birthweight. Epidemiology 1996, 7, 377-383.

9. Pfinder, M.; Feldmann, R. Prenatal alcohol exposure: Long-term effects to the child. Suchttherapie 2011, 12, 109-114.

10. Streissguth, A.P.; Aase, J.M.; Sterling, K.C.; Randels, S.P.; LaDue, R.A.; Smith, D.F. Fetal alcohol syndrome in adolescents and adults. JAMA 1991, 265, 1961-1967.

11. Bergmann, R.L.; Richter, R.; Milto, C.; Michel, B.; Dudenhausen, J.W. Epidemiologie des Alkoholkonsums in der Schwangerschaft. In Alkohol in der Schwangerschaft-Häufigkeit und Folgen; Bergmann, R.L., Spohr, H.L., Dudenhausen, J.W., Eds.; Urban \& Vogel: München; Germany, 2006; pp. 19-32.

12. Ethen, M.; Ramadhani, T.; Scheuerle, A.; Canfield, M.; Wyszynski, D.; Druschel, C.; Romitti, P. Alcohol consumption by women before and during pregnancy. Matern. Child Health J. 2009, 13, 274-285.

13. Jaddoe, V.W.; Bakker, R.; Hofman, A.; Mackenbach, J.P.; Moll, H.A.; Steegers, E.A.; Witteman, J.C.M. Moderate alcohol consumption during pregnancy and the risk of low birth weight and preterm birth. The Generation R Study. Ann. Epidemiol. 2007, 17, 834-840.

14. Kruse, J.; le Fevre, M.; Zweig, S. Changes in smoking and alcohol consumption during pregnancy: A population-based study in a rural area. Obstet. Gynecol. 1986, 67, 627-632.

15. Palma, S.; Pardo-Crespo, R.; Mariscal, M.; Perez-Iglesias, R.; Llorca, J.; Delgado-Rodríguez, M. Weekday but not weekend alcohol consumption before pregnancy influences alcohol cessation during pregnancy. Eur. J. Public Health 2007, 17, 394-399.

16. Pfinder, M.; Feldmann, R.; Liebig, S. Alcohol during pregnancy from 1985 to 2005: Prevalence and high risk profile. Sucht 2013, 59, 165-173.

17. Prager, K.; Malin, H.; Spiegler, D.; van Natta, P.; Placek, P.J. Smoking and drinking behaviour before and during pregnancy of married mothers of live-born infants and stillborn infants. Public Health Rep. 1984, 99, 117-127.

18. Abel, E.L. Fetal Alcohol Abuse Syndrome; Plenum Press: New York, NY, USA, 1998.

19. Abel, E.L.; Hannigan, J.H. Maternal risk factors in fetal alcohol syndrome. Provocative and permissive influences. Neurotoxicol. Teratol. 1995, 17, 445-462. 
20. Bingol, N.; Schuster, C.; Fuchs, M.; Iosub, S.; Turner, G.; Stone, R.K.; Gromisch, D.S. The influence of socioeconomic factors on the occurrence of fetal alcohol syndrome. Adv. Alcohol Subst. Abuse 1987, 6, 105-118.

21. Burd, L.; Cotsonas-Hassler, T.M.; Martsolf, J.T.; Kerbeshian, J. Recognition and management of fetal alcohol syndrome. Neurotoxicol. Teratol. 2003, 25, 681-688.

22. May, P.A.; Gossage, J.P.; Brooke, L.E.; Snell, C.L.; Marais, A.-S.; Hendricks, L.S; Croxford, J.A.; Viljoen, D.L. Maternal risk factors for fetal alcohol syndrome in the western cape province of South Africa: A population-based study. Amer. J. Public Health 2005, 95, 1190-1199.

23. May, P.A.; Gossage, J.P.; Marais, A.-S.; Hendricks, L.S.; Snell, C.L.; Tabachnick, B.G.; Stellavato, C.; Buckley, D.G.; Brooke, L.E.; Viljoen, D.L. Maternal risk factors for fetal alcohol syndrome and partial fetal alcohol syndrome in South Africa: A third study. Alcohol. Clin. Exp. Res. 2008, 32, 738-753.

24. May, P.A.; Gossage, J.P.; White-Country, M.; Goodhart, K.; Decoteau, S.; Trujillo, P.M.; Kalberg, W.O.; Viljoen, D.L.; Hoyme, H.E. Alcohol consumption and other maternal risk factors for fetal alcohol syndrome among three distinct samples of women before, during, and after pregnancy: The risk is relative. Amer. J. Med. Genet. 2004, 127C, 10-20.

25. Streissguth, A.P.; Bookstein, F.L.; Barr, H.M.; Sampson, P.D.; O’Malley, K.; Young, J.K. Risk factors for adverse life outcomes in fetal alcohol syndrome and fetal alcohol effects. J. Dev. Behav. Pediat. 2004, 25, 228-238.

26. Barker, D.J.P. Fetal origins of coronary heart disease. BMJ 1995, 311, 171-174.

27. Barker, D.J.P. Mothers, Babies and Health in Later Life, 2nd ed.; Churchill Livingstone: London, UK, 1998.

28. Barker, D.J.P.; Osmond, C. Infant mortality, childhood nutrition and ischaemic heart disease in England and Wales. Lancet 1986, 327, 1077-1081.

29. Ben-Shlomo, Y.; Kuh, D. A life course approach to chronic disease epidemiology: Conceptual models, empirical challenges and interdisciplinary perspectives. Int. J. Epidemiol. 2002, 31, 285-293.

30. Conley, D.; Bennett, N.G. Is biology destiny? Birth weight and life chances. Amer. Sociol. Rev. 2000, 65, 458-467.

31. Graham, H.; Power, C. Childhood disadvantage and health inequalities: A framework for policy based on lifecourse research. Child Care Health 2004, 30, 671-678.

32. Kuh, D.; Ben-Shlomo, Y.; Lynch, J.; Hallqvist, J., Power, C. Life course epidemiology. J. Epidemiol. Community Health 2003, 57, 778-783.

33. Rossing, P.; Tarnow, L.; Nielsen, F.S.; Hansen, B.V.; Brenner, B.M.; Parving, H.H. Low birth weight. A risk factor for development of diabetic nephropathy. Diabetes 1995, 44, 1405-1407.

34. Pfinder, M.; Liebig, S.; Feldmann, R. Explanation of social inequalities in hyperactivity/inattention in children with prenatal alcohol exposure. Klin. Padiat. 2012, 224, 303-308.

35. Brooke, O.G.; Anderson, H.R.; Bland, J.M.; Peacock, J.L.; Stewart, C.M. Effects on birth weight of smoking, alcohol, caffeine, socioeconomic factors, and psychosocial stress. Br. Med. J. 1989, 298, 795-801.

36. Chomitz, V.R.; Cheung, L.W.Y.; Lieberman, E. The role of lifestyle in preventing low birth weight. Future Child. 1995, 5, 121-138. 
37. Kleinman, J.C.; Madans, J.H. The effects of maternal smoking, physical stature, and educational attainment on the incidence of low birth weight. Amer. J. Epidemiol. 1985, 121, 843-855.

38. Kogan, M.D. Social causes of low birth weight. J. R. Soc. Med. 1995, 88, 611-615.

39. Kramer, M.S. Determinants of low birth weight: Methodological assessment and meta-analysis. Bull. World Health Organ. 1987, 65, 663-737.

40. Sexton, M.; Hebel, J.R. A clinical trial of change in maternal smoking and its effects on birth weight. JAMA 1984, 251, 911-915.

41. Wang, X.; Zuckerman, B.; Pearson, C.; Kaufman, G.; Chen, C.; Wang, G.; Niu, T.; Wise, P.H.; Bauchner, $\mathrm{H}$.; $\mathrm{Xu}, \mathrm{X}$. Maternal cigarette smoking, metabolic gene polymorphism, and infant birth weight. JAMA 2002, 287, 195-202.

42. Henkel, D.; Zemlin, U.; Dornbusch, P. Sozialschicht und Konsum von Alkohol und Tabak im Bundesgesundheitssurvey 1998. Sucht 2003, 49, 306-311.

43. Aliyu, M.H.; Wilson, R.E.; Zoorob, R.; Brown, K.; Alio, A.P.; Clayton, H.; Salihu, H.M. Prenatal alcohol consumption and fetal growth restriction: Potentiation effect by concomitant smoking. Nicotine Tob. Res. 2009, 11, 36-43.

44. Haste, F.M.; Anderson, H.R.; Brooke, O.G.; Bland, J.M.; Peacock, J.L. The effects of smoking and drinking on the anthropometric measurements of neonates. Paediatr. Perinat. Epidemiol. 1991, 5, 83-92.

45. Olsen, J.; Pereira, A.D.C.; Olsen, S.F. Does maternal tobacco smoking modify the effect of alcohol on fetal growth? Amer. J. Public Health 1991, 81, 69-73.

46. Verkerk, P.H.; van Noord-Zaadstra, B.M.; Du, V.; Florey, C.; de Jonge, G.A.; Verloove-Vanhorick, S.P. The effect of moderate maternal alcohol consumption on birth weight and gestational age in a low risk population. Early Hum. Dev. 1993, 32, 121-129.

47. Chihara, I.; Hayes, D.K.; Chock, L.R.; Fuddy, L.J.; Rosenberg, D.L.; Handler, A.S. Relationship between gestational weight gain and birthweight among clients enrolled in the special supplemental nutrition program for women, infants, and children (WIC), Hawaii, 2003-2005. Matern. Child Health J. 2013, doi:10.1007/s10995-013-1342-6.

48. Griffiths, L.J.; Dezateux, C.; Cole, T.J.; Millenium Cohort Study Child Health Group. Differential parental weight and height contributions to offspring birthweight and weight gain in infancy. Int. J. Epidemiol. 2007, 36, 104-107.

49. Halfon, N.; Lu, M.C. Gestational weight gain and birth weight. Lancet 2010, 376, 937-938.

50. Morrison, J.; Williams, G.M.; Najman, J.M.; Andersen, M.J. The influence of paternal height and weight on birth-weight. Aust. N. Z. J. Obstet. Gynaecol. 1991, 31, 114-116.

51. Shrestha, I.; Sunuwar, L.; Bhandary, S.; Sharma, P. Correlation between gestational weight gain and birth weight of the infants. Nepal Med. Coll. J. 2010, 12, 106-109.

52. Witter, F.R.; Luke, B. The effect of maternal height on birth weight and birth length. Early Hum Dev. 1991, 25,181-186.

53. Kramer, M.S.; Séguin, L.; Lydon, J.; Goulet, L. Socio-economic disparities in pregnancy outcome: Why do the poor fare so poorly? Paediatr. Perinat. Epidemiol. 2000, 14, 194-210.

54. Subramanian, S.V.; Özaltin, E.; Finlay, J.E. Height of nations: A socioeconomic analysis of cohort differences and patterns among women in 54 low- to middle-income countries. PLoS One 2011, 6, doi:10.1371/journal.pone.0018962. 
55. Subramanian, S.V.; Perkins, J.M.; Khan, K.T. Do burdens of underweight and overweight coexist among socioeconomic groups in India? Amer. J. Clin. Nutr. 2009, 90, 369-376.

56. Kurth, B.M.; Kamtsiuris, P.; Hölling, H.; Schlaud, M.; Dölle, R.; Ellert, U.; Kahl, H.; Knopf, H.; Lange, M.; Mensink, G.B.M.; et al. The challenge of comprehensively mapping children's health in a nation-wide health survey: Design of the German KiGGS-Study. BMC Public Health 2008, 8 , doi:10.1186/1471-2458-8-196.

57. Seghieri, G.; Anichini, R.; de Bellis, A.; Alviggi, L.; Franconi, F.; Breschi, M.C. Relationship between gestational diabetes mellitus and low maternal birth weight. Diabetes Care 2002, 25, 1761-1765.

58. Winkler, J. Die Messung des Sozialen Status mit Hilfe eines Index in den Gesundheitssurveys der DHP. In Messung Soziodemographischer Merkmale in der Epidemiologie; Ahrens, W., Bellach, B., Jöckel, K.-H., Eds.; MMV Medizin Verlag: München, Germany, 1998; pp. 69-74.

59. Winkler, J.; Stolzenberg, H. Der Sozialschichtindex im Bundesgesundheitssurvey. Gesundheitswesen 1999, 61, 178-183.

60. Winkler, J.; Stolzenberg, H. Adjustierung des Sozialen-Schicht-Index für die Anwendung im Kinder- und Jugendgesundheitssurvey (KiGGS) 2003/2006 In Wismarer Diskussionspapiere; Kramer, J.W., Ed.; HWS-Hochschule Wismar Service GmbH: Wismar, Germany, 2009; Volume 7, pp. 1-28.

61. Scheuch, E.K. Sozialprestige und soziale Schichtung. Kolner Z. Soziol. Sozialpsychol. 1970, 5, 65-103.

62. Nohr, E.A.; Vaeth, M.; Baker, J.L.; Sørensen, T.I.A.; Olsen, J.; Rasmussen, K.M. Combined associations of prepregnancy body mass index and gestational weight gain with the outcome of pregnancy. Amer. Clin. Nutr. 2008, 87, 1750-1759.

63. Obesity: Preventing and Managing the Global Epidemic. Report of a WHO Consultation. WHO Technical Report Series 894; World Health Organization: Geneva, Switzerland, 2000.

64. Baron, R.M.; Kenny, D.A. The moderator-mediator variable distinction in social psychological research: Conceptual, strategic, and statistical considerations. J. Personal Soc. Psychol. 1986, 51, 1173-1182.

65. MacKinnon, D.P.; Krull, J.L.; Lockwood, C.M. Equivalence of the mediation, confounding and suppression effect. Prev. Sci. 2000, 1, 173-181.

66. Alvik, A.; Haldorsen, T.; Groholt, B.; Lindemann, R. Alcohol consumption before and during pregnancy comparing concurrent and retrospective reports. Alcohol. Clin. Exp. Res. 2006, 30, 510-515.

67. Ernhart, C.B.; Morrow-Tlucak, M.; Sokol, R.J.; Martier, S. Underreporting of alcohol use in pregnancy. Alcohol. Clin. Exp. Res. 1988, 12, 506-511.

68. Jacobson, S.W.; Jacobson, J.L.; Sokol, R.J.; Martier, S.S.; Ager, J.W.; Kaplan, M.G. Maternal recall of alcohol, cocaine, and marijuana use during pregnancy. Neurotoxicol. Teratol. 1991, 13, 535-540.

69. Morrow-Tlucak, M.; Ernhart, C.B.; Sokol, R.J.; Martier, S.; Ager, J. Underreporting of alcohol use in pregnancy: Relationship to alcohol problem history. Alcohol. Clin. Exp. Res. 1989, 13, $399-401$. 
70. Bakker, R.; Kruithof, C.; Steegers, E.A.; Tiemeier, H.; Mackenbach, J.P.; Hofman, A.; Jaddoe, V.W. Assessment of maternal smoking status during pregnancy and the associations with neonatal outcomes. Nicotine Tob. Res. 2011, 13, 1250-1256.

71. Boyd, N.H.; Windsor, R.A.; Perkins, L.L.; Lowe, J.B. Quality of measurement of smoking status by self-report and saliva cotinine among pregnant women. Matern. Child Health J. 1998, 2, 77-83.

72. De Weerd, S.; Thomas, C.M.G.; Cikot, R.J.L.M.; Steegers, E.A.P. Maternal smoking cessation intervention: Targeting women and their partners before pregnancy. Amer. J. Public Health 2001, 91, 1733-1734.

73. Ford, R.P.K.; Tappin, D.M.; Schluter, P.J.; Wild, C.J. Smoking during pregnancy: How reliable are self-reports in New Zealand? J. Epidemiol. Community Health 1997, 51, 246-251.

74. Astrup, P.; Trolle, D.; Olsen, H.M.; Kjeldsen, K. Effect of moderate carbon-monoxide exposure on fetal development. Lancet 1972, 300, 1220-1222.

75. Cnattingius, S. The epidemiology of smoking during pregnancy: Smoking prevalence, maternal characteristics, and pregnancy outcomes. Nicotine Tob. Res. 2004, 6, 125-140.

76. James, W.P.T.; Nelson, M.; Ralph, A.; Leather, S. Socioeconomic determinants of health: The contribution of nutrition to inequalities in health. BMJ 1997, 314, 1545.

77. Suzuki, K.; Horiguchi, T.; Comas-Urrutia, A.C.; Mueller-Heubach, E.; Morishima, H.O.; Adamsons, K. Pharmacologic effects of nicotine upon the fetus and mother in the rhesus monkey. Amer. J. Obstet. Gynecol. 1971, 111, 1092-1101.

78. Blickstein, I.; Jacques, D.L.; Keith, L.G. Effect of maternal height on gestational age and birth weight in nulliparous mothers of triplets with a normal pregravid body mass index. J. Reprod. Med. 2003, 48, 335-338.

79. Jananthan, R.; Wijesinghe, D.G.N.G.; Sivananthawerl, T. Maternal anthropometry as a predicator of birth weight. Trop. Agr. Res. 2009, 21, 89-98.

80. Miletić, T.; Stoinil, E.; Mikulandra, F.; Tadin, I.; Roje, D.; Milić, N. Effect of parental anthropometric parameters on neonatal birth weight and birth length. Collegium Antropol. 2007, 31, 993-997.

81. Pickett, K.E.; Abrams, B.; Selvin, S. Maternal height, pregnancy weight gain, and birthweight. Amer. J. Hum. Biol. 2000, 12, 682-687.

82. Edwards, L.E.; Alton, I.R.; Barrada, M.I.; Hakanson, E.Y. Pregnancy in the underweight woman. Course, outcome, and growth patterns of the infant. Amer. J. Obstet. Gynecol. 1979, 135, 297-302.

83. Han, Z.; Mulla, S.; Beyene, J.; Liao, G.; McDonald, S.D. Maternal underweight and the risk of preterm birth and low birth weight: A systematic review and meta-analyses. Int. J. Epidemiol. 2011, 40, 65-101.

(C) 2014 by the author; licensee MDPI, Basel, Switzerland. This article is an open access article distributed under the terms and conditions of the Creative Commons Attribution license (http://creativecommons.org/licenses/by/3.0/). 